\title{
Crimean-Congo hemorrhagic fever: a comprehensive review
}

\author{
Aman Kamboj ${ }^{1}$ and Himanshu Pathak ${ }^{2}$
}

1. Division of Veterinary Biotechnology, Indian Veterinary Research Institute (IVRI)

Izatnagar- 243122, Dist. Bareilly, Uttar Pradesh, India; 2. Division of Animal Biochemistry, Indian Veterinary Research Institute (IVRI) Izatnagar- 243122, Dist. Bareilly, Uttar Pradesh, India

Corresponding author: Himanshu Pathak, Email: vethimanshu@gmail.com

Received: 26-06-2013, Revised: 28-07-2013, Accepted: 30-07-2013, Published online: 08-09-2013

doi: 10.14202 /vetworld.2013.812-817

How to cite this article: Kamboj $A$ and Pathak $H$ (2013) Crimean-Congo hemorrhagic fever: a comprehensive review, Veterinary World 6(10): 812-817.

\begin{abstract}
Crimean-Congo Hemorrhagic Fever (CCHF) is an emerging tick-born zoonotic disease in India which is caused by Nairovirus of Bunyaviridae family. CCHF is reported from about 30 countries of the world. An outbreak of CCHF has been reported two years back in Gujarat which killed four people including two physicians, one nurse and a rural housewife. Tick bite, contact with infected material and nosocomial routes are the main routes of infection. This disease is not much important in animals as animals are asymptomatic but domestic livestock play a vital role in the transmission of disease to humans. So the persons associated with animals like veterinarians, farmers and slaughter house workers are also at the high risk of getting the infection. The disease has a great public health importance. Rapid diagnosis of disease is very important. The advent of molecular techniques including real-time PCR allow the rapid diagnosis of CCHF. There are limited treatment options for CCHF. Ribavirin is the only known drug which is effective against CCHF.
\end{abstract}

Keywords: biosafety, Crimean-Congo hemorrhagic fever, nosocomial, zoonotic disease

\section{I ntroduction}

Infectious diseases are the leading contributors of mortality and morbidity in humans and animals across the globe. Many emerging diseases, even epidemics are a direct consequence of zoonosis. Some infectious diseases like viral hemorrhagic fevers (VHFs)are a matter of great concern due to their zoonotic nature and associated fatality. VHFs are now becoming a severe threat to animals and humans. Crimean-Congo hemorrhagic fever (CCHF) is one of the most widely distributed viral hemorrhagic fevers among these [1]. It is an emerging zoonotic disease which has drawn attention of international community . Although, it is new to India, outbreaks have been recorded from various countries in Africa, Asia, South-East Europe, and Middle East [2].

$\mathrm{CCHF}$ is a tick born viral zoonotic disease caused by virus of genus Nairovirus of Bunyaviridae family [3]. The disease is distributed globally which can be correlated by the global distribution of the tick vector (Hyalomma tick) which is responsible for viral transmission [2]. The disease has been recognized by different names as Asian Ebola, Hungribta (blood taking), Khunymuny (nose bleeding) or Karakhalak (Black Death) in the different parts of world [4]. In the last 2 years, in India, CCHF is emerging as an important zoonotic disease and a potential threat for the persons associated with animals as farmers, animal handlers and veterinarians due to its potential transmission from animal to human. However, human-

Copyright: The authors. This article is an open access article licensed under the terms of the Creative Commons Attribution License (http://creativecommons.org/licenses/by/2.0) which permits unrestricted use, distribution and reproduction in any medium, provided the work is properly cited. to-human transmission also reported in some cases in various countries [2].

\section{History}

CCHF was first described in the Crimea, Russia in 1944 by soviet scientists during an outbreak which involved 200 cases of CCHF in soviet military personnel. They called it Crimean hemorrhagic fever (CHF) [3]. Later in 1956 it was found that the causative agent was identical to a virus isolated from a patient in Congo and the name CCHF was adopted after that [5].

\section{Epidemiology and geographical distribution}

CCHFV has a mostextensive geographic distribution among all tick viruses and it is widespread in Eurasia and Africa [6,7]. The geographic distribution pattern of disease coincides with the distribution of Hyalomma tick vector. The virus is reported from about 30 countries which include Africa (Uganda, Sudan, Democratic Republic of Congo, Nigeria, Mauritania, Senegal and South Africa etc), Southeast Europe (Kosovo, Russia, Bulgaria, Greece and Turkey etc.), Middle East (Iraq, Iran, Saudi Arabia and Oman) and Asia (Kazakhstan, Tajikistan, Uzbekistan, Pakistan, China and India) $[8,9,10]$.

In Africa, due to limited sanitary facilities, virus surveillance is difficult. In the last decade lesser than 100 cases were reported in Africa and most of the cases occurred in South Africa [11]. In 2003, outbreak occurred in Mauritania [12] and in 2008, a nosocomial outbreak was reported in Sudan $[11,13]$.

In Europe, Bulgaria is the only country where $\mathrm{CCHF}$ is endemic but outbreaks have been recorded with increased number of cases in other countries like Kosovo, Turkey, Albania, Ukraine and South-west of 
the Russian Federation [14]. Between 1997 and 2009, a total of $159 \mathrm{CCHF}$ cases were identified in Bulgaria [15]. In Turkey also, an increased number of CCHF cases were reported between year 2002 and 2009[16]. CCHF is also widespread in Asia and middle-east [2, 8]. Some of the recent outbreaks are listed in Table-1. Recently in September of 2010, an outbreak was reported in Pakistan's Khyber Pakhtunkhwa province [17]. So, India is always at potential risk of acquiring CCHFV from its neighbors.

Table-1. Recent outbreaks of CCHF

\begin{tabular}{llc}
\hline Year & Location/Country & References \\
\hline 2008 & Bulgaria & {$[18]$} \\
2008 & Sudan & {$[13]$} \\
2008 & Turkey & {$[19]$} \\
2009 & Iran & {$[20]$} \\
2009 & Kazakhstan & {$[21]$} \\
2009 & Tajikistan & {$[22]$} \\
2009 & Afghanistan & {$[23]$} \\
2010 & Pakistan & {$[17]$} \\
2011 & India & {$[24]$} \\
\hline
\end{tabular}

Seasonal variations have been reported in the occurrence of CCHF. In Iran, higher number of cases reported in August and September [25]. In Pakistan high incidence is common between March and May, and again between August and October, showing biannual surge [26]. Climatic change is always a contributing factor for the occurrence of disease that affects the reproduction of tick population resulting in increased incidence of tick born infections [27, 28].

The first documented outbreak of CCHF in India was reported from Ahmedabad, Gujarat province of western India in December 2010 [24]. Four human deaths occurred among which the first victim a 32-year old housewife of Korat village in Sanand died on January $3^{\text {rd }}, 2011$ [29]. The 35-year-old doctor treating her died on $13^{\text {th }}$ January, 2011 and an accompanying nurse died on $18^{\text {th }}$ January, 2011 [29]. The National Institute of Virology (NIV), Pune confirmed the positive testing of CCHFV, identified for the first time in India [29]. A 25-year-old doctor working as a medical intern became the next victim of CCHF virus and died on 31st January [29]. He was the second doctor and fourth victim overall to die of deadly disease in Ahmedabad. All deaths have occurred in less than a month $[29,30]$. The death pattern shows that all the persons died of CCHF were living in close association of livestock or were the doctors treating the infected cases.

Transmission from tick or animal-to-human: Animals do not show clinical signs but may act as a source of infection for humans [31]. The virus is transmitted from animals to humans either by direct contact with blood or tissue of infected animal. The tick biting or crushing of tick on skin or mucous membrane may be potential routes for transmission of CCHFV from tick to human [32].

Human-to-human transmission: Human- to- human transmission occurs by direct contact of virus contaminated blood or tissues from infected patient. This may occur primarily in hospital setting causing nosocomial infection [20]. Aerosol or airborne infection is also reported in Russia [32]. There may be horizontal transmission from a mother to her child which indicates the need of preventive measures for inhouse outbreaks of CCHF [33].

\section{Causative agent}

CCHFV is a member of Nairovirus genus of the Bunyaviridae family [3]. It is enveloped spherical virus approximately $100 \mathrm{~nm}$ in diameter [4]. The lipid envelope is host derived, 5-7 nm thick, through which glycoprotein spikes, $8-10 \mathrm{~nm}$ in length protrude out $[34,35]$. The genome, around $19.2 \mathrm{~kb}$, consists of three segments of negative sense single stranded RNA segments designated as Large (L), Medium (M) and Small (S) and encode for viral polymerase (L), Glycoprotein precursor (GPC) and Nucleocapsid (N) respectively [36]. A schematic representation of CCHFV genome is given in the Figure-1. The latter two form the structural proteins. The Glycoprotein precursor undergoes proteolytic processing to form structural proteins $\mathrm{Gn}(37 \mathrm{kDa})$ and $\mathrm{Gc}(75 \mathrm{kDa})$ and possible non structural proteins (mucin,GP160, GP85, GP38 and NSm). In case of Indian isolate L, M and S segments are $12166 \mathrm{bp}, 5396 \mathrm{bp}$ and $1667 \mathrm{bp}$ long and encode proteins of $444.6 \mathrm{kDa}, 186.9 \mathrm{kDa}$ and 53.97 $\mathrm{kDa}$ respectively [36].

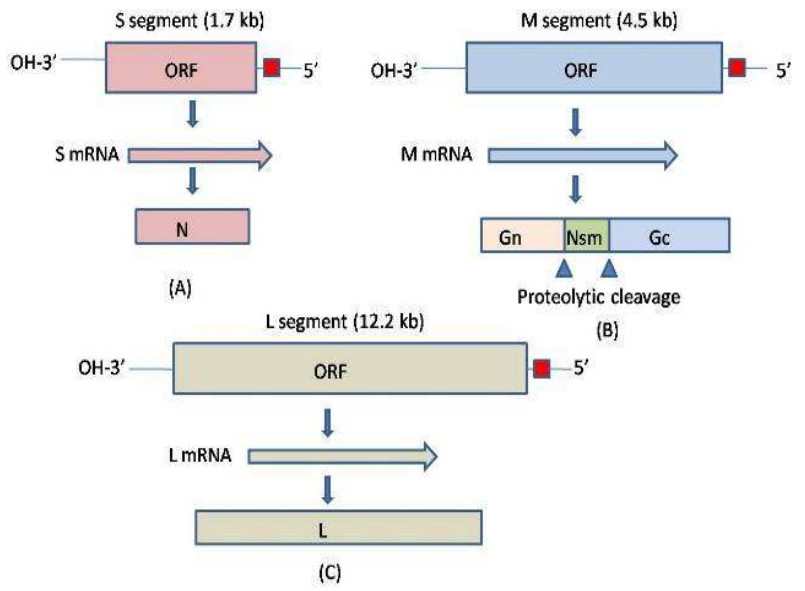

Figure-1. Schematic representation of CCHFV genome. (A). S segment encodes for nucleocapsid, (B). M segment encodes glycoprotein precursor which undergo proteolytic cleavage to form structural proteins Gc and Gn and non-structural protein Nsm., (C). L segment encodes for viral polymerase. (self-designed figure)

\section{Phylogenetic diversity in CCHFV}

Previous studies based on serological testing suggested very few significant differences among CCHFV strains [5]. However studies based on nucleic acid sequencing analysis revealed extensive global genetic diversity [37, 38]. The phylogenetic study of various CCHFV S, M and $\mathrm{L}$ segment sequences available revealed the formation of distinct groups [38]. The virus isolates circulating in our neighboring country Pakistan is having considerable variation in $\mathrm{S}$ segment sequence from the Indian isolates [36]. So the 
possibility of introduction of CCHFV from the neighboring country cannot be ruled out. The phylogenetic study of Indian isolates performed by Yadav P. D. et al (2012) revealed that the S segment was closest to a Tajikistan strain TADJ/ HU8966 of SouthAsia 2 type while the $M$ segment was found to be of type M2 [36] . Both M and L segments were closest to an Afghanistan strain Afg09-2990. Thus the Indian isolates were found as a South-Asia 2/M2 far-east virus combination and it may be an intra-genotypic reassortant [36].

\section{Reservoir and vector}

Like other tick born zoonotic agents, CCHFV follows an enzootic tick-vertebrate-tick cycle [1, 4]. There is no evidence of clinical disease in animals but a wide range of domestic and wild animals act as reservoir for CCHFV $[2,31]$. The CCHFV has been isolated from various domestic and wild animals including cattle, sheep, goats, hares, hedgehogs, mice (Mastomys spp.) and domestic dogs [4, 32]. On serological testing the antibodies against CCHFV has been found in various wild and domestic animals even in a Tortoise in Tajikistan [32]. Most of the birds are thought to be resistant to CCHF infection; however some reports are available in ostriches where experimentally infection was produced $[39,40]$. In South Africa, cases have been reported where the persons working in commercial ostrich slaughter house suffered from disease [41]. Birds may transfer the virus infected ticks even though they themselves remain non-viremic.In a study recently CCHF was detected in the ticks from migratory birds in Morocco [42]. So the migratory birds may be a reason of transport of virus from one place to other distinct places [42, 43]. Apart from migratory birds, international trade and transport of livestock carrying ticks may transport virus from one country to other [43].

Tick act as both reservoir as well as vector for CCHFV. CCHFV can infect a number of ticks of Ixodidae family but particularly ticks of genus Hyalomma are the most common and efficient vectors of CCHFV [32, 40]. Transovarial, transtadial and venereal mode of transmission of virus is found in vector [32]. So the tick remains infected throughout its life and transfer virus from one generation to next generation. Immature ticks feed on the blood of small animals while the mature tick transfer infection to large animals including domestic livestock [1,3].

\section{Clinical features and pathogenesis}

CCHFV infections are asymptomatic in animals and birds are thought to be resistant. Humans are the main victims to this disease. The course of the disease can be divided into four phases- incubation, prehemorrhagic, hemorrhagic and convalescence [3]. The incubation period depends on the mode of infection. Infections acquired via tick bites usually become apparent after 1-3 days [4]. Exposure to blood or tissues results in longer incubation period. In Indian cases, the incubation period ranged from 7-12 days through the later mode [4, 24, 29].

Pre-hemorrhagic symptoms are non specific and include fever, chills, severe headache, dizziness, photophobia, myalgia and arthralagia. This phase may last for 1-7 days [44]. The hemorrhagic phase develops suddenly lasting for 2-3 days [44]. A petechial rash may be the first symptom both on the internal mucosal surfaces such as mouth and throat and on the skin. They are followed by ecchymoses and other hemorrhagic phenomenon such as hematemesis, melena, epistaxis, hematuria, and hemoptysis. Hepatomegaly and spleenomegaly can be seen in some patients [31, 45]. There may be rapid kidney deterioration. Death may occur in many cases. The mortality rate is $30 \%$ and the case fatality rate is up to40\%[40]. In Indian cases death occurred due to cardio respiratory arrest, multiorgan failure and disseminated intravascular coagulation (DIC) and gastrointestinal bleeding in one case [29]. In patients who survive recovery begins 10-20 days after onset of illness. Recovery may take up to a year [24].

No clear pathogenesis is described for CCHF. Endothelial damage is a common feature leading to capillary fragility and accounts for the characteristic rash and contributes to hemostatic failure by stimulating platelet aggregation and degranulation [4]. Thrombocytopenia occurs and dysregulation of the coagulation cascade leads to DIC. Proinflammatory cytokines are important in pathogenesis and the IL6and TNF- $\alpha$ level are significantly higher in fatal CCHF [46].A study shows that viral genome can be detected from saliva and urine of infected patient [47]. In $\mathrm{CCHF}$ there is increased serum ferritin level which can be used as a marker for disease activity and prognosis [48].

\section{Public health importance}

Humans readily succumb to CCHFV infection. However domestic animals are either refractory or undergo mild infection with transient viremia sometimes, but they act as a main source of infection for humans [49]. Persons living in close contact with animals are at the high risk of getting CCHF. Veterinarians and farmers may castrate, dehorn, attach ear tags and immunize young animals and thus expose themselves to the virus infected blood. They may have broken skin or scratch on the skin through which they may get infected. Consumption of unboiled or uncooked meat and milk of infected animal may be a potential source of infection [2]. There is lack of evidence of disease in urban consumers of meat but the infected animal may reach to abattoir to pose a potential threat for workers and meat consumers. Exposure to aerosols while working with infected animals and in the hospital setting are the potential hazards. The population in the infected or infection prone area should be aware of the potential routes of infection and the safety measures to be taken to avoid 
the infection[40]. CCHFV may be used for bioterrorism or as a biowarfare agent [2]. Due to this it is included in CDC/NIAID Category C Pathogen [32].

\section{Diagnosis}

To save the patient and to prevent the further transmission of disease, early diagnosis is essential. The key indicators to suspect CCHF infection includes compatible clinical manifestations like fever and bleeding, history of tick bite, travel to endemic area and contact with infected cases and tick infested animals. The disease should be differentiated from the other VHFs, malaria, dengue, yellow fever, Kyasanur forest disease, rickettsiosis and leptospirosis [31, 50]. The knowledge of ecology and endemicity of CCHFV should be kept in mind to proceed with further diagnosis. The methods of diagnosis include virus isolation, immunological assays like ELISA and molecular diagnostic methods like reverse transcription- polymerase chain reaction (RT-PCR) $[1$, 32].

CCHFV can be isolated from the blood, plasma and tissue of infected patient for the diagnosis. Virus isolation should be performed in a high biocontainment laboratory [31]. A variety of cell lines including vero, BHK-21, LLC-MK2 and SW-13 can be used for virus culture [51]. Cell culture can detect only high virus concentration and only useful during first five days of disease. Generally the virus produces no or little cytopathic effects so it can be identified by immunofluorescence assay using specific monoclonal antibodies [4]. The traditional method of animal inoculation of newborn mice is more sensitive than cell culture and also detects the virus for longer period [52]. The virus isolation by cell culture is of limited value because it needs a biosafety level-4 laboratory (BSL-4) which is unavailable in most of the endemic areas [31]. In the first few days of illness usually the patients do not develop a measurable antibody response so the serological tests are useful in the second week of illness [1]. There are various serological tests available for detection of CCHFV but these tests are of limited use in fatal cases as patients generally die without developing antibodies. The conventional serological test for CCHFV like Complement fixation, heamagglutination inhibition and immunodiffusion suffered lack of sensitivity and reproducibility [3]. This problem was solved by IndirectImmunofluorescence assay (IFA) and Enzyme-linked immunosorbent assay (ELISA) for the detection of $\operatorname{IgM}$ and $\operatorname{IgG}$ antibodies. Both $\operatorname{IgM}$ and IgG can be detected up to 7-9 days of illness by indirect FIA $[4,53]$. ELISA has replaced the conventional methods for antibody detection. IgM can be detected up to 4 months and $\mathrm{IgG}$ persist for 5 years post infection but its level decrease [4].

Molecular diagnostic assays such as reverse transcriptase polymerase chain reaction now serve as the front-line tool in the diagnosis of CCHF [54]. PCR based methods are sensitive, specific, rapid and can be done without the need to culture the virus which requires BSL-4 facility [4]. Molecular epidemiology can also be performed by this technique. A further improvement on the conventional RT-PCR assay has been the advent of automated real-time PCR based assays. The real-time PCR is more advantageousover conventional RT-PCR methods with respect to sensitivity, specificity and time taken for detection. Real- time PCR also offers less contamination rate. There are various detection chemistries available for the real time PCR like SYBR green, TaqMan and molecular beacon etc. There are several real-time RTPCR assays reported till now for CCHFV detection. Some important assays developed for CCHFV detection are SYBR green, TaqMan and TaqManMinor Groove Binding (MGB) probe based assays [54, $55,56]$.

\section{Treatment}

In case of CCHF, treatment is mainly supportive. It includes careful management of fluid and electrolyte balance depending upon the severity of illness [1]. Currently there is no specific antiviral therapy for CCHF approved by United States Food and Drug Administration (FDA) for human use [30]. Ribavarin, a guanosine analogue is found effective against CCHFV [57-59]. CCHFV is susceptible to ribavirin in vitro [58]. According to some reports oral and intravenous ribavirin is effective for treating CCHFV infections[18]. In India one case recovered by the oral administration of ribavirin and discharged after ten days [50]. Passive immunotherapy using specific immunoglobulin CCHF-Venin is also found beneficial in CCHFV treatment [30].

\section{Prevention and control}

The prevention and control should be both at community level as well as in nosocomial set up. Minimizing human contact with suspected livestock and reducing the tick burden in the animals are the primary and most important preventive measures [40]. Animals should be carefully monitored for tick infestation and treated by appropriate acaricidal agents particularly before slaughter or export. Wearing fully covered clothes and use of tick repellent is recommended to prevent tick attachment on the body surface. The unpasteurized milk and uncooked meat should not be taken. Human- to- human infection mainly occurs in the nosocomial setup by the contact of infected blood or tissue. So use of protective clothing, gloves, goggles and face-masks reduces the chances of exposure [59]. Safe burial practices with proper use of disinfectants should be followed. Veterinarians, research workers, slaughter house workers and medical professionals should take utmost care to reduce the contact with suspected material. They should take the prophylactic treatment after high risk exposure. Laboratory and research workers are advised to follow stringent biosafety precautions during handling the pathogen and the work should be carried out under 
BSL-4 facilities. Virus can be inactivated by using $1 \%$ hypochlorite and $2 \%$ glutaraldehyde [32]. Heating at $56^{\circ} \mathrm{C}$ for 30 minutes also destroy the virus [32].

Vaccination: Vaccine against CCHF is not available in most of the countries. However a formalin inactivated vaccine derived from suckling mouse brain has been used in Bulgaria and former Soviet Union [60]. There is no vaccine available for animal use [40].

\section{Conclusion}

CCHF is an emerging disease in India. Its zoonotic potential and fatality have created a great havoc in the general population as well as in health care community. Since animals play an important role in the transmission of virus to human, the persons associated with animals are at the great risk of CCHFV infection. This disease is new to India so people should be aware of the various aspects of this fatal disease mainly its modes of transmission, clinical manifestations, public health importance and preventive measures.

\section{References}

1. Mardani, M. and Jahromi, M.K. (2007) Crimean-Congo Hemorrhagic Fever.Archives of Iranian Medicine, 10(2): $204-214$.

2. Ergonul, O. (2006) Crimean-Congo hemorrhagic fever. Lancet Infect Dis, 6: 203-14.

3. Hoogstraal, H. (1979) The epidemiology of tick-borne Crimean-Congo hemorrhagic fever in Asia, Europe and Africa.J Med Entomol, 15: 307-417.

4. Whitehouse, C. A. (2004) Crimean-Congo hemorrhagic fever. Antiviral Res, 64: 145-160.

5. Casals, J. (1969) Antigenic similarity between the virus causing Crimean hemorrhagic fever and Congo virus. Proc Soc Exp Biol Med, 131: 233-236.

6. Maltezou, H.C. and Papa, A. (2011) Crimean-Congo hemorrhagic fever: epidemiological trends and controversies in treatment. BMC Medicine, 9:131.

7. Leblebicioglu, H. (2010) Crimean-Congo haemorrhagic fever in Eurasia. Int J Antimicrob Agents, 36(Suppl):S43-46.

8. Zavitsanou, A., Babatsikou, F. and Koutis, C. (2009) Crimean Congo Hemorrhagic fever: an emerging tick-borne disease. Health Science Journal, 3(1):10-18.

9. Morikawa, S., Saijo, M. and Kurane, I. (2007) Recent progress in molecular biology of Crimean-Congo hemorrhagic fever. Comp ImmunolMicrobiol Infect Dis, 30: 375-89.

10. Koutis, C.H. (2007) Special Epidemiology. Editions, Technological Educational Institute of Athens. Athens, Greece.

11. Grard, G., Drexler, J.F., Fair, J., Muyembe, J.J., Wolfe, N.D., Drosten, C. and Leroy, E.M. (2011) Re-Emergence of Crimean-Congo Hemorrhagic Fever Virus in Central Africa. PLoSNegl TropDis, 5(10): e1350.

12. Nabeth, P., Cheikh, D.O., Lo, B., Faye, O., Vall, I.O.,Niang, M., Wague, B., Diop, D., Diallo, M., Diallo, B., Diop, O.M. and Simon, F.(2004) Crimean-Congo hemorrhagic fever, Mauritania. Emerg Infect Dis, 10: 2143-2149.

13. Aradaib, I.E, Erickson, B.R., Mustafa, M.E., Khristova, M.L., Saeed, N.S., Elageb, R.M. and Nichol, S.T.(2010) Nosocomial outbreak of Crimean-Congo hemorrhagic fever, Sudan. Emerg Infect Dis, 16:837-839.

14. Maltezou, H.C., Andonova, L., Andraghetti, R., Bouloy, M., Ergonul, O., Jongejan, F., Kalvatchev, N., Nichol, S., Niedrig, M., Platonov, A., Thomson, G., Leitmeyer, K. and Zeller, H. (2010) Crimean-Congo hemorrhagic fever in Europe: current situation calls for preparedness.
EuroSurveill, 15(10):pii=19504.

15. Vescio, F.M., Busani, L., Mughini-Gras, L., Khoury, C., Avellis, L., Taseva, E., Rezza, G. and Christova, I. (2012) Environmental correlates of Crimean-Congo haemorrhagic fever incidence in Bulgaria. BMC Public Health, 12:1116.

16. Ozdarendeli, A., Canakoglu, N., Berber, E., Aydin, K., Tonbak, S., Ertek, M., Buzgan, T., Bolat, Y., Aktas, M. and Kalkan, A. (2010)The complete genome analysis of Crimean-Congo hemorrhagic fever virus isolated in Turkey. Virus Research, 147: 288-293.

17. ProMED-mail. Crimean-Congo hem. fever - Pakistan (09): (NW). ProMED-mail. (2010) Oct. 15. 20090715.2529.

18. Christova, I., Di Caro, A., Papa, A., Castilletti, C., Andonova, L., Kalvatchev,, N.,Papadimitriou, E., Carletti, F., Mohareb, E., Capobianchi, M. R., Ippolito, G. and Rezza, G.( 2009) Crimean-Congo hemorrhagic fever, southwestern Bulgaria. Emerg Infect Dis, 15:983-985.

19. Uyar, Y., Carhan, A., Albayrak, N. and Altaş, A.B. (2010) Evaluation of PCR and ELISA-IgM results in the laboratory diagnosis of Crimean-Congo haemorrhagic fever cases in 2008 in Turkey. MikrobiyolBul, 44:57-64.

20. Naderi, H.R., Sarvghad, M.R., Bojdy, A., Hadizadeh, M.R., Sadeghi, R. and Sheybani, F. (2010) Nosocomial outbreak of Crimean-Congo haemorrhagic fever. Epidemiol Infect, 27: $1-5$.

21. ProMED-mail. Crimean-Congo hem. fever - Kazakhstan: (SK) ProMEDmail. (2009) Jul 15. 20090715.2529.

22. ProMED-mail. Crimean-Congo hem. fever - Tajikistan: (TC). ProMED-mail. (2009) Aug 15. 20090815.2898.

23. Mustafa, M.L., Ayazi, E., Mohareb, E., Yingst, S., Zayed, A., Rossi, C.A., Schoepp, R.J., Mofleh, J., Fiekert, K., Akhbarian, Z., Sadat, H. and Leslie, T. (2011)CrimeanCongo Hemorrhagic Fever, Afghanistan, 2009. Emerging Infectious Diseases, 17 (10): 1940-41.

24. Patel, A.K., Patel, K.K., Mehta, M., Parikh, T.M., Toshniwal, H. and Patel, K. (2011) First Crimean-Congo Hemorrhagic Fever Outbreak in India. JAPI, 59:585-88.

25. Mardani, M. and Bijani, B. (2003)Clinico-epidemiologic features and outcome analysis of hemorrhagic forms of Crimean-Congo hemorrhagic fever (CCHF) in Iran. 41st Annual Meeting of IDSA, October 9 - 12, 2003; SanDiego,United States: 763.

26. Sheikh, A.S., Sheikh, A.A., Sheikh, N.S., Rafi, U.S., Asif, M. and Afridi, F. (2005) Bi-annual surge of Crimean-Congo hemorrhagic fever (CCHF): a five-year experience. Int $J$ Infect Dis, 9: 37-42.

27. Gubler, D.J., Reiter, P., Ebi, K.L., Yap, W., Nasci, R. and Patz, J.A. (2001) Climate variability and change in the United States: potential impacts on vector- and rodent-borne diseases. Environ Health Perspect, 109: 223 - 233.

28. Estrada-Pena, A. (2001) Forecasting habitat suitability for ticks and prevention of tick-borne diseases. VetParasitol, 98: $111-132$.

29. Mourya, D.T., Yadav, P.D., Shete, A.M., Gurav, Y.K., Raut, C.G., Jadi, R.S., Pawar, S.D., Nichol, S.T. and Mishra, A.C. (2012) Detection, Isolation and Confirmation of CrimeanCongo Hemorrhagic Fever Virus in Human, Ticks and Animals in Ahmadabad, India, 2010-2011. PLoSNegl Trop Dis, 6(5): e1653.

30. Khan, N.A., Jaiswal, A., Choudhray, R., Abid, M. and Kishore, K. (2011) Crimean-Congo hemorrhagic fever: An article review. Int Res JPharma, 2(5): 33-40.

31. Ergonul, O. (2013)Crimean-Congo hemorrhagic fever virus: new outbreaks, new discoveries. Current Opinion in Virology, 2:215-220.

32. The Center for Food Security \& Public Health. (2007) Crimean-Congo Haemorrhagic Fever. http://www. cfsph. iastate.edu/Factsheets/pdfs/crimean_congo_hemorrhagic_f ever.pdf. Accessed on 20-05-2013.

33. Masayuki, S., Qing, T., Bawudong, S., Lei, H. and Yuzhen, Z. (2004) Possible horizontal transmission of Crimean-Congo hemorrhagic fever virus from a mother to her child. Jpn $J$ Infect Dis, 57: 55 - 57 . 
34. Marriott, A.C. and Nuttall, P.A. (1996) Molecular biology of nairoviruses. In: Elliott, R.M. (Ed.), TheBunyaviridae. Plenum Press, New York. 91-104.

35. Schmaljohn, C.S and Hooper, J.W. (2001)Bunyaviridae: the viruses and their replication. In: Knipe, D. M. andHowley, P. M. (Eds.), Fields Virology. vol. 1, fourth ed. Lippincott, Williams \& Wilkins, Philadelphia. 1581-1602.

36. Yadav, P.D., Cherian, S.S., Zawar, D., Kokate, P., Gunjikar, R., Jadhav, S., Mishra, A.C. and Mourya, D.T. (2013) Genetic characterization and molecular clock analyses of the Crimean-Congo hemorrhagic fever virus from human and ticks in India, 2010-2011. Infection, Genetics and Evolution, 14: 223-231.

37. Anagnostou, V. and Papa, A. (2009) Evolution of CrimeanCongo Hemorrhagic Fever virus. Infection, Genetics and Evolution, 9: 948-954.

38. Deyde, V.M., Khristova, M.L., Rollin, P.E., Ksiazek, T.G. and Nichol, S.T. (2006) Crimean-Congo hemorrhagic fever virus genomics and global diversity. JVirol, 80: 8834-8842.

39. Swanepoel, R., Leman, P.A., Burt, F.J., Jardine, J., Verwoerd, D.J., Capua, I., Bruckner, G.K. and Burger, W.P. (1998) Experimental infection of ostriches with Crimean-Congo haemorrhagic fever virus. Epidemiol Infect, 121: 427-432.

40. World Health Organization (2013) WHO Fact Sheet No. 208. WHO, Geneva, Switzerland.

41. Van-Eeden, P.J., Joubert, J.R., Van de wal, B.W., King, J.B., de Kock, A. and Groenewald, J.H. (1985) A nosocomial outbreak of Crimean-Congo haemorrhagic fever at Tygerberg Hospital. Part I. Clinical features. S Afr Med J, 68:711-717.

42. Palomar, A.M., Portillo, A., Santibáñez, P., Mazuelas, D., Arizaga, J., Crespo, A., Gutierrez, O., Cuadrado, J.F. and Oteo, J.A. (2013)Crimean-Congo Hemorrhagic Fever Virus in Ticks from Migratory Birds, Morocco. Emerg Infect Dis, 19 (2):260-263.

43. Aradaib, I.E., Erickson, B.R., Karsany, M.S., Khristova, M.L., Elageb, R.M., Mohamed, E.H. and Nichol, S.T. (2011) Multiple Crimean-Congo Hemorrhagic Fever Virus Strains Are Associated with Disease Outbreaks in Sudan, 2008-2009. PLoSNegl Trop Dis, 5(5): e1159.

44. Saijo, M. and Morikawa, S. (2010) Recent progress in the treatment of Crimean- Congo hemorrhagic fever and future perspectives. Future virology, 5(6): 801-9.

45. Appannanavar, S.B. and Mishra, B. (2011)An Update on Crimean-Congo Hemorrhagic Fever. J Glob Infect Dis, 3(3): 285-292.

46. Ergonul, O., Tuncbilek, S., Baykam, N., Celikbas, A. and Dokuzoguz, B. (2006) Evaluation of serum levels of IL-6, IL-10, and TNF-alpha in patients with Crimean-Congo hemorrhagic fever. J Infect Dis, 193: 941 - 944.

47. Bodur, H., Akinci, E., Onguru, P., Carhan, A., Uyar, Y.,Tanrici, A.,Cataloluk, O. and Kubar, A. (2009) Detection of Crimean-Congo hemorrhagic fever virus genome in saliva and urine. International Journal of Infectious Diseases, 14: e247-e249.

48. Barut, S., Dincer, F., Sahin, I., Ozyurt, H., Akkus, M. and Erkorkmaz, U. (2010) Increased serum ferritin levels in patients with Crimean-Congo hemorrhagic fever: can it be a new severity criterion? International Journal of Infectious Diseases, 14: e50—e54.

49. Prajapati, D.S., Patel, K.M., Patel, R.K., Sen, D.J., Patel, J.S. and Garg, C.S. (2011)Crimean-congo hemorrhagic fever from tick-borne viral disease. Int J Compreh Pharm, 3(2). 1-6.

50. Mishra, A.C., Mehta, M., Mourya, D.T. and Gandhi, S. (2011)Crimean-Congo haemorrhagic fever in India. Lancet, 378: 372.

51. Nichol, S.T. (2001)Bunyaviruses. In: Knipe, D.M. andHowley, P.M. (Eds.), Fields Virology, vol. 1, fourth ed. Lippincott, Williams \& Wilkins, Philadelphia, 1603-1633.

52. Shepherd, A.J., Swanepoel, R., Leman, P.A. and Sherpherd, S.P. (1986) Comparison of methods for isolation and titration of Crimean-Congo hemorrhagic fever virus. J Clin Microbiol, 24: 654-656.

53. Donets, M.A., Rezapkin, G.V., Ivanov, A.P. and Tkachenko, E.A. (1982) Immunosorbent assays for diagnosis of Crimean-Congo haemorrhagic fever (CCHF). Am J Trop MedHyg, 31:156-162.

54. Drosten, C., Kummerer, B.M., Schmitz, H. and Gunther, S. (2003) Molecular diagnostics of viral hemorrhagic fevers. Antiviral Res, 57: 61-87.

55. Wölfel, R., Paweska, J.T., Petersen, N., Grobbelaar, A.A., Leman, P.A., Hewson, R., Georges-Courbot, M.C., Papa, A., Günther, S. and Drosten, C. (2007) Virus Detection and Monitoring of Viral Load in Crimean-Congo Hemorrhagic Fever Virus Patients.Emerg Infect Dis, 13(7):1097-1100.

56. Garrison, A.R., Alakbarova, S., Kulesh, D.A., Shezmukhamedova, D., Khodjaev, S., Endy, T.P. and Paragas, J. (2007) Development of a TaqMan-Minor Groove Binding Protein Assay for the Detection and Quantification of Crimean-Congo Hemorrhagic Fever Virus.Am J Trop MedHyg, 77(3): 514-520.

57. Izadi, S. and Salehi, M. (2009) Evaluation of the Efficacy of Ribavirin Therapy on Survival of Crimean-Congo Hemorrhagic Fever Patients. A Case-Control Study. Jpn J Infect Dis, 62: 11-15.

58. Watts, D.M., Ussery, M.A., Nash, D. and Peters, C.J. (1989) Inhibition of Crimean-Congo hemorrhagic fever viral infectivity yields in in-vitro by ribavirin. Am J Trop MedHyg, 41:581-585.

59. Bajpai, S. and Nadkar, M.Y. (2011) Crimean Congo Hemorrhagic Fever: Requires Vigilance and Not Panic JAPI, 59:164-167.

60. Papa, A., Papadimitriou, E. and Christova, I. (2011) The Bulgarian vaccine Crimean-Congo haemorrhagic fever virus strain. Scand J Infect Dis, 43:225-9. 